\title{
CEMS AND RF-MÖSSBAUER STUDY OF NANOCRYSTALLINE $\mathrm{Fe}_{81} \mathrm{Zr}_{7} \mathrm{~B}_{12}$ ALLOY
}

\author{
M. Kopcewicz, A. Grabias \\ Institute of Electronic Materials Technology, Wölczyniska 133, 01-919 Warszawa, Poland \\ AND P. NowICKI \\ Department of Materials Science and Engineering, Warsaw University of Technology \\ Narbutta 85, 02-524 Warszawa, Poland
}

\begin{abstract}
The combined conversion electron (CEMS) and $\gamma$-transmission Mössbauer spectroscopy is used to investigate the differences in the bulk and surface crystallization of the amorphous $\mathrm{Fe}_{81} \mathrm{Zr}_{7} \mathrm{~B}_{12}$ alloy. The radio-frequency induced effects ( $\mathrm{rf}$ collapse and side bands) are used to study the microstructure and magnetic behaviour of the alloy in the amorphous and nanocrystalline states. Rf-Mössbauer experiment permits us to distinguish soft magnetic nanocrystalline bcc-Fe phase from microcrystalline $\alpha$-Fe.
\end{abstract}

PACS numbers: $76.80 .+\mathrm{y}, 75.50 . \mathrm{Kj}, 75.50 . \mathrm{Bb}, 81.40 .-\mathrm{z}$

Amorphous $\mathrm{FeZrBCu}$ alloys are very promising systems for obtaining nanocrystalline structure with high saturation magnetization and good soft magnetic properties [1,2]. Annealing of the amorphous precursor causes formation of nanoscale grains of bcc Fe which exhibit high saturation magnetization combined with low anisotropy and coercive fields and vanishing magnetostriction.

The crystallization and magnetic properties of nanocrystalline alloys have been investigated by various techniques including the Mössbauer spectroscopy. However, information regarding the grain size and magnetic anisotropy is not available by conventional Mössbauer measurements. In order to investigate the differences in the bulk and surface crystallization of amorphous FeZrB alloys we used the combined conversion electron (CEMS) and transmission Mössbauer spectroscopy which allowed simultaneous study of the surface layer (about $100 \mathrm{~nm}$ thick) and of the bulk of the sample. The magnetic properties were studied by an unconventional technique which combines the Mössbauer effect with the phenomena induced by an external radio-frequency field ( $r f$ collapse and side-band effects) (see e.g. [3]). The collapse of the magnetic hyperfine splitting occurs due to fast magnetization reversal induced by an external radio-frequency magnetic field as a result of which the magnetic hyperfine field is averaged to zero at the Mössbauer nuclei though the sample remains in the ferromagnetic state. The rf collapse is very sensitive to small changes of local magnetic anisotropy, which allows distinction of the soft nanocrystalline phase from the magnetically harder microcrystalline 
phases formed by annealing of the amorphous precursor. The rf side-band effect, directly related to magnetostriction, allows identification of the nanocrystalline phase thanks to vanishing magnetostriction.

In this paper, we report on CEMS, transmission and rf-Mössbauer studies of $\mathrm{Fe}_{93-x-y} \mathrm{Zr}_{7} \mathrm{~B}_{x} \mathrm{Cu}_{y}$ alloys in amorphous and nanocrystalline states. Although a whole series of alloys with $x=6,8,12$ and $y=0,2$ were studied only the results for the $\mathrm{Fe}_{81} \mathrm{Zr}_{7} \mathrm{~B}_{12}$ alloy are discussed here, since it reveals the highest Curie temperature in this set of samples.

In order to obtain the nanocrystalline phase, amorphous ribbons were an. nealed for $1 \mathrm{~h}$ at temperatures $T_{\mathrm{A}}=430-780^{\circ} \mathrm{C}$. The CEMS and conventional transmission Mössbauer measurements were performed for the as-quenched and annealed samples. The rf-Mössbauer measurements were performed during exposure of the samples to the rf field of $20 \mathrm{Oe}$ at $60.8 \mathrm{MHz}$ which was applied in the plane of the sample. The isomer shift data are given with respect to the $\alpha-\mathrm{Fe}$ standard. The details of the experimental procedure are given elsewhere [4].

The transmission and CEMS spectra obtained are shown in Fig. 1. The spectra of samples annealed at $T_{\mathrm{A}} \leq 600^{\circ} \mathrm{C}$ (Figs. $1 \mathrm{a}-\mathrm{e}$ and $\left.1 \mathrm{a}^{\prime}-\mathrm{e}^{\prime}\right)$ were fitted by the combination of the hyperfine field distribution $(P(H))$ related to the amorphous phase and subspectra with discrete values of hyperfine fields $\left(H_{\mathrm{hf}}\right)$ and isomer shifts $(\delta)$ corresponding to the crystalline bcc Fe $\left(H_{\mathrm{hf}}=32.95 \mathrm{~T}, \delta=0.00 \mathrm{~mm} / \mathrm{s}\right)$ and the tetragonal $\mathrm{Fe}_{2} \mathrm{~B}$ phase (two components with $H_{\mathrm{hf} 1}=23.2 \mathrm{~T}$ and $H_{\mathrm{hf} 2}=24.2 \mathrm{~T}$ and $\delta_{1}=0.12 \mathrm{~mm} / \mathrm{s}$ and $\delta_{2}=0.11 \mathrm{~mm} / \mathrm{s}$, respectively [5]). The $P(H)$ distribution was calculated by the histogram method [6].

As can be seen from Fig. 1 the transmission and CEMS spectra of the as-quenched alloy are identical. However, clear differences between the bulk and surface crystallization appear already at $T_{\mathrm{A}}=430^{\circ} \mathrm{C}$. The transmission spectrum (Fig. 1b) consists of the spectral component characteristic of the purely amorphous state in which no crystalline phases could be detected, while the CEMS spectrum (Fig. $1 \mathrm{~b}^{\prime}$ ) reveals, beside that component, the sextet characteristic of the bcc-Fe phase. Thus crystallization started at the surface already at $T_{\mathrm{A}}=430^{\circ} \mathrm{C}$. A similar situation was observed for the sample annealed at $500^{\circ} \mathrm{C}$ (Figs. $1 \mathrm{c}$ and $1 \mathrm{c}^{\prime}$ ). The spectral contribution in CEMS spectrum of the sextet characteristic of bcc Fe increases markedly with increasing $T_{\mathrm{A}}$. At $T_{\mathrm{A}}=550^{\circ} \mathrm{C}$ the bcc-Fe phase appears in the bulk (Fig. 1d). The relative fraction of this phase is, however, much lower than that at the surface (Fig. $1 d^{\prime}$ ).

In the spectra of the samples annealed at $T_{\mathrm{A}}=430,500$ and $550^{\circ} \mathrm{C}$ beside the bcc-Fe sextet, a paramagnetic component, not observed in any transmission spectra, consisting of the quadrupole splitting $(Q S)$ doublet $(Q S \approx 0.80 \mathrm{~mm} / \mathrm{s}$ and $\delta \approx 0.34 \mathrm{~mm} / \mathrm{s}$ ) is clearly seen (Figs. $1 \mathrm{~b}^{\prime}, 1 \mathrm{c}^{\prime}$ and $1 \mathrm{~d}^{\prime}$ ). The origin of this nonmagnetic component is uncertain. However, the observed $Q S$ and $\delta$ values correspond quite well to those characteristic of the iron-poor paramagnetic amorphous $\mathrm{FeB}$ phase [7]. Such a phase could appear at the surface as a result of segregation of some iron atoms from the amorphous matrix to form the bcc-Fe phase. The amorphous $\mathrm{FeB}$ phase is unstable and decomposes with progressing bulk and surface crystallizations which occur at higher annealing temperatures.

The CEMS spectrum of the sample annealed at $T_{\mathrm{A}}=600^{\circ} \mathrm{C}\left(\mathrm{Fig} .1 \mathrm{e}^{\prime}\right)$ reveals 


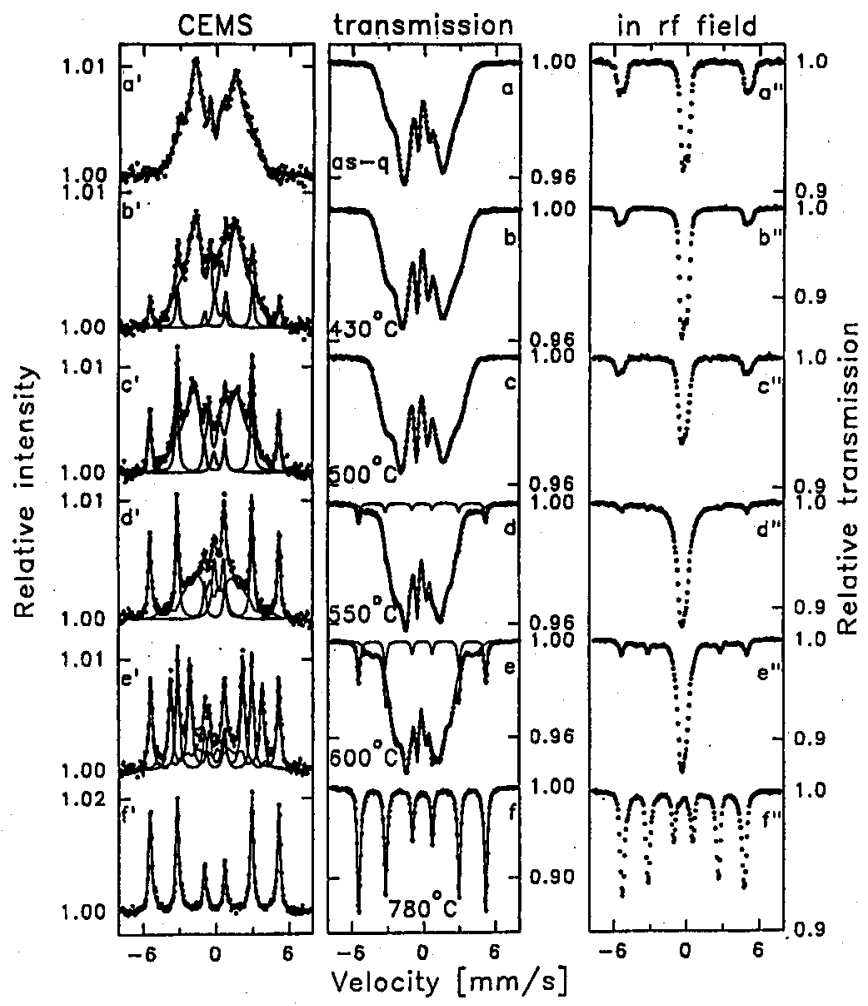

Fig. 1. CEMS $\left(\left(a^{\prime}\right)-\left(f^{\prime}\right)\right)$ and transmission Mössbauer spectra recorded in the absence of the rf field $((\mathrm{a})-(\mathrm{f}))$ and during rf exposure $\left(\left(\mathrm{a}^{\prime \prime}\right)-\left(\mathrm{f}^{\prime \prime}\right)\right)$ for $\mathrm{Fe}_{81} \mathrm{Zr}_{7} \mathrm{~B}_{12}$ alloy in the as-quenched state and after 1 hour annealing at $430-780^{\circ} \mathrm{C}$.

that in addition to the bcc-Fe phase the crystalline $\mathrm{Fe}_{2} \mathrm{~B}$ phase was formed. This phase is formed only at the surface of the sample.

In all CEMS and transmission spectra of the samples annealed at $T_{\mathrm{A}}=500$, 550 and $600^{\circ} \mathrm{C}$ a spectral component with $H_{\mathrm{hf}} \approx 27.5 \div 29 \mathrm{~T}$ and $\delta \approx 0.04 \mathrm{~mm} / \mathrm{s}$ was observed. We attribute this sextet to the grain boundary regions between the nanocrystalline bcc $\mathrm{Fe}$ and the amorphous host.

The higher annealing temperature $\left(T_{\mathrm{A}}=780^{\circ} \mathrm{C}\right)$ causes complete bulk crystallization of the alloy. Both transmission and CEMS spectra consist only of one sextet characteristic of the $\alpha$-Fe phase (Figs. 1f and 1f') which suggests that iron atoms are completely separated from other alloy components.

The Mössbauer spectra measured during the exposure to the rf field are shown in Figs. 1a"- $\mathrm{f}^{\prime \prime}$. A complete collapse of the magnetic hyperfine structure to a quadrupole doublet is observed for the amorphous alloy (Figs. $1 a^{\prime \prime}-c^{\prime \prime}$ ). The rf side bands clearly seen in the spectrum of the as-quenched alloy (Fig. 1a ${ }^{\prime \prime}$ ) decrease markedly for the sample annealed at $500^{\circ} \mathrm{C}$ (Fig. $1 \mathrm{c}^{\prime \prime}$ ). The formation of the nanocrystalline bcc-Fe phase causes a dramatic change of the shape of the rf-collapsed spectrum (Fig. $1 d^{\prime \prime}$ ). The central collapsed part consists now of a 
superposition of a single line corresponding to cubic nanocrystalline bcc-Fe phase and a quadrupole doublet corresponding to the retained amorphous matrix. The rf side bands disappear completely which shows that magnetostriction almost vanished. However, the noncollapsed spectral component appears with sharp lines (Figs. 1d", 1e $\mathrm{e}^{\prime \prime}$ ) corresponding to bcc-Fe phase in the form of grains with magnetic anisotropy large enough to prevent the rf collapse. The spectrum recorded during rf exposure for the microcrystalline sample (Fig. If $f^{\prime \prime}$ ) shows noncollapsed six-line component similar to that corresponding to magnetically harder microcrystalline $\alpha$-Fe (Fig. 1f). These results are discussed in detail elsewhere [4].

Conventional CEMS and transmission Mössbauer measurements allow identification of phases formed at the surface and in the bulk by annealing of the starting amorphous alloys but do not provide information concerning the magnetic anisotropy of the grains. The rf-Mössbauer experiments, in which the rf collapse and side band effects are observed, permit us to distinguish the soft nanocrystalline bcc-Fe phase from magnetically harder microcrystalline $\alpha$-Fe. Some information concerning grain size distribution can be obtained. The nanocrystalline bcc-Fe phase is identified by the appearance of a single line component in the rf collapsed spectrum and by the disappearance of rf side bands due to vanishing magnetostriction.

\section{Acknowledgments}

Financial support from grant ITME 01-1-1032-6 and EC-Copernicus projects (NOCOMO CIPA-CT 94.0208 and ERB CIPA-CT 94-0155) is gratefully acknowledged.

\section{References}

[1] K. Suzuki, A. Makino, A. Inoue, T. Masumoto, J. Appl. Phys. 70, 6232 (1991).

[2] K. Suzuki, A. Makino, A. Inoue, T. Masumoto, J. Appl. Phys. 74, 3316 (1993).

[3] M. Kopcewicz, Struct. Chem. 2, 313 (1991).

[4] M. Kopcewicz, A. Grabias, P. Nowicki, D.L. Williamson, J. Appl. Phys. 79, 993 (1996).

[5] L. Takacs, M.C. Cadeville, I. Vincze, J. Phys. F 5, 800 (1975).

[6] G. Le Caer, J.M. Dubois, J. Phys. E 12, 1083 (1979).

[7] W. Hoving, F. van der Woude, K.H.J. Buschow, in: Proc. Fifth Int. Conf. on Rapidly Quenched Metals, Eds. S. Steeb, H. Warlimont, North-Holland, Amsterdam 1985, p. 549. 